BMJ Open Sport \& Exercise Medicine

\title{
Can marathon running improve knee damage of middle-aged adults? A prospective cohort study
}

\author{
Laura Maria Horga (D) , J Johann Henckel, ${ }^{1}$ Anastasia Fotiadou, ${ }^{1}$ \\ Anna Hirschmann, ${ }^{2}$ Camilla Torlasco, ${ }^{3}$ Anna Di Laura, ${ }^{1}$ Andrew D'Silva (D) ,
} Sanjay Sharma, ${ }^{4}$ James Moon, ${ }^{3}$ Alister Hart ${ }^{1}$

To cite: Horga LM, Henckel J, Fotiadou A, et al. Can marathon running improve knee damage of middle-aged adults? A prospective cohort study. BMJ Open Sport \& Exercise Medicine 2019;5:e000586. doi:10.1136/ bmjsem-2019-000586

- Additional material is published online only. To view please visit the journal online (http://dx.doi.org/10.1136/ bmjsem-2019-000586).

Accepted 29 September 2019

Check for updates

(c) Author(s) (or their employer(s)) 2019. Re-use permitted under CC BY-NC. No commercial re-use. See rights and permissions. Published by BMJ

${ }^{1}$ Institute of Orthopaedics and Musculoskeletal Science, Royal National Orthopaedic Hospital, University College London, London, UK

${ }^{2}$ Clinic of Radiology and Nuclear Medicine, University Hospital

Basel, University of Basel, Basel, Switzerland

${ }^{3}$ Institute of Cardiovascular

Science and Barts Heart Centre, University College London,

London, UK

${ }^{4}$ Department of Cardiovascular Sciences, St. George's University of London, London, UK

Correspondence to Dr Laura Maria Horga; laura.horga.17@ucl.ac.uk

\section{ABSTRACT}

Objectives To evaluate the short-term impact of longdistance running on knee joints using MRI.

Methods 82 healthy adults participating in their first marathon underwent 3T (Tesla) MRI of both knees 6 months before and half a month after the marathon: 71 completed both the 4 month-long standardised training programme and the marathon; and 11 dropped-out during training and did not run the marathon. Two senior musculoskeletal radiologists graded the internal knee structures using validated scoring systems. Participants completed Knee Injury and Osteoarthritis Outcome Score questionnaires at each visit for self-reporting knee function.

Results Premarathon and pretraining MRI showed signs of damage, without symptoms, to several knee structures in the majority of the 82 middle-aged volunteers. However, after the marathon, MRI showed a reduction in the radiological score of damage in: subchondral bone marrow oedema in the condyles of the tibia $(p=0.011)$ and femur $(p=0.082)$. MRI did also show an increase in radiological scores to the following structures: cartilage of the lateral patella $(p=0.0005)$; semimembranosus tendon $(p=0.016)$; iliotibial band $(p<0.0001)$ and the prepatellar bursa $(\mathrm{p}=0.016)$

Conclusion Improvement to damaged subchondral bone of the tibial and femoral condyles was found following the marathon in novice runners, as well as worsening of the patella cartilage although asymptomatic. This is the most robust evidence to link marathon running with knee joint health and provides important information for those seeking to understand the link between long distance running and osteoarthritis of the main weight-bearing areas of the knee.

\section{INTRODUCTION}

Long-distance running has become a popular phenomenon worldwide, with more than 30 million individuals running marathons each year. ${ }^{1}$ Running exerts repetitive stress on the lower extremities, especially the knee joint, therefore, in excess, can lead to injuries and the development of osteoarthritis ${ }^{23}$

Preparation for a marathon run has been linked to an incidence of musculoskeletal

\section{What are the new findings?}

- The main weight-bearing compartments presenting subchondral bone marrow oedema before the marathon, in asymptomatic middle-aged adults, showed reversibility following the training for and completion of running a marathon.

- The patellofemoral compartment was the region most injured by marathon running.

- Marathon running did not result in progression of meniscal tears and their presence did not affect performance.

How might it impact on clinical practice in the future?

Study findings could help inform marathon running-related decision making.

- During training for a marathon, injury prevention exercises that target those areas of the knee which are more susceptible to damage, especially the patellofemoral joint, should be considered.

- Runners, clinicians and the general public can use this data for a better understanding of the effect of high-intensity exercise on the knee.

problems as high as $90 \%,{ }^{4}$ especially at the knee joint including patellofemoral pain. ${ }^{5}$ As many participants are first-time runners, with the number of older marathoners being significantly on the rise, ${ }^{67}$ this has given rise to increasing health concerns.

Few studies have investigated the effects of marathon running on the internal knee structures. MRI is the perfect tool to assess whether running a marathon changes the 'normal structure of the knee', and the high resolution 3 Tesla (T) MRI gives unprecedented precision in detecting subtle changes and pathologies in the structure. ${ }^{89}$

Evidence is lacking robustness, as to whether long-distance running, often on hard surfaces such as roads, is bad for the knees. Evidence has relied on small numbers of subjects $(<22$ 
participants) and a variety of study designs, for example, low MR field strength (1.5T or less), varying follow-ups, different knee structures being assessed, unclear clinical significance, and differences in the scoring systems used for each knee structure. ${ }^{10-17}$

We aimed to better understand the effect of marathon running on the knee joint by performing high resolution 3T MRI scans of both knees of first-time marathon runners before and after running a marathon.

\section{METHODS}

\section{Study design and participants}

This was a prospective, longitudinal cohort study. All volunteers provided written, informed consent before participation.

We recruited 115 healthy asymptomatic volunteers (51 males, 64 females, median age: 44 years, range: 25-73 years) who were registered for their first marathon (the 2017 London Marathon). The main inclusion criteria were: sedentary, ${ }^{18}$ novice marathon runners with no present knee injury/history of knee injury or cardiac abnormalities. Volunteers were screened for good cardiovascular health by our cardiac team who used ECG, exercise stress testing and cardiac MRI. Pregnant women, individuals aged $<18$ years, experienced runners, with known knee problems or poor cardiovascular health were excluded from the study.

All volunteers underwent bilateral knee 3T MRI scans 2 months before a 4-month standardised gradual training programme for the marathon. Thirty-one of our enrolled cohort failed to complete the training programme and were considered 'non-marathon runners' (see figure 1) due to reasons not directly linked to their pretraining health condition: bradycardia $(n=1)$, bronchitis $(n=1)$, knee pain during training $(n=2)$, calf issue $(n=2)$, plantar fasciitis $(n=1)$, Achilles tendinitis $(n=1)$, metatarsal stress fracture $(n=2)$, personal reasons $(n=2)$ and undisclosed reasons $(n=19)$.

Eighty-three participants completed the marathon, 71 of these attended the clinic for a second MRI scan half a month after the marathon, as did 11 of the 31 non-marathon runners who failed to complete the training and did not start the marathon. Non-marathon runners were used for comparison with the marathon runners' group (figure 1; and table 1 for full participant characteristics).

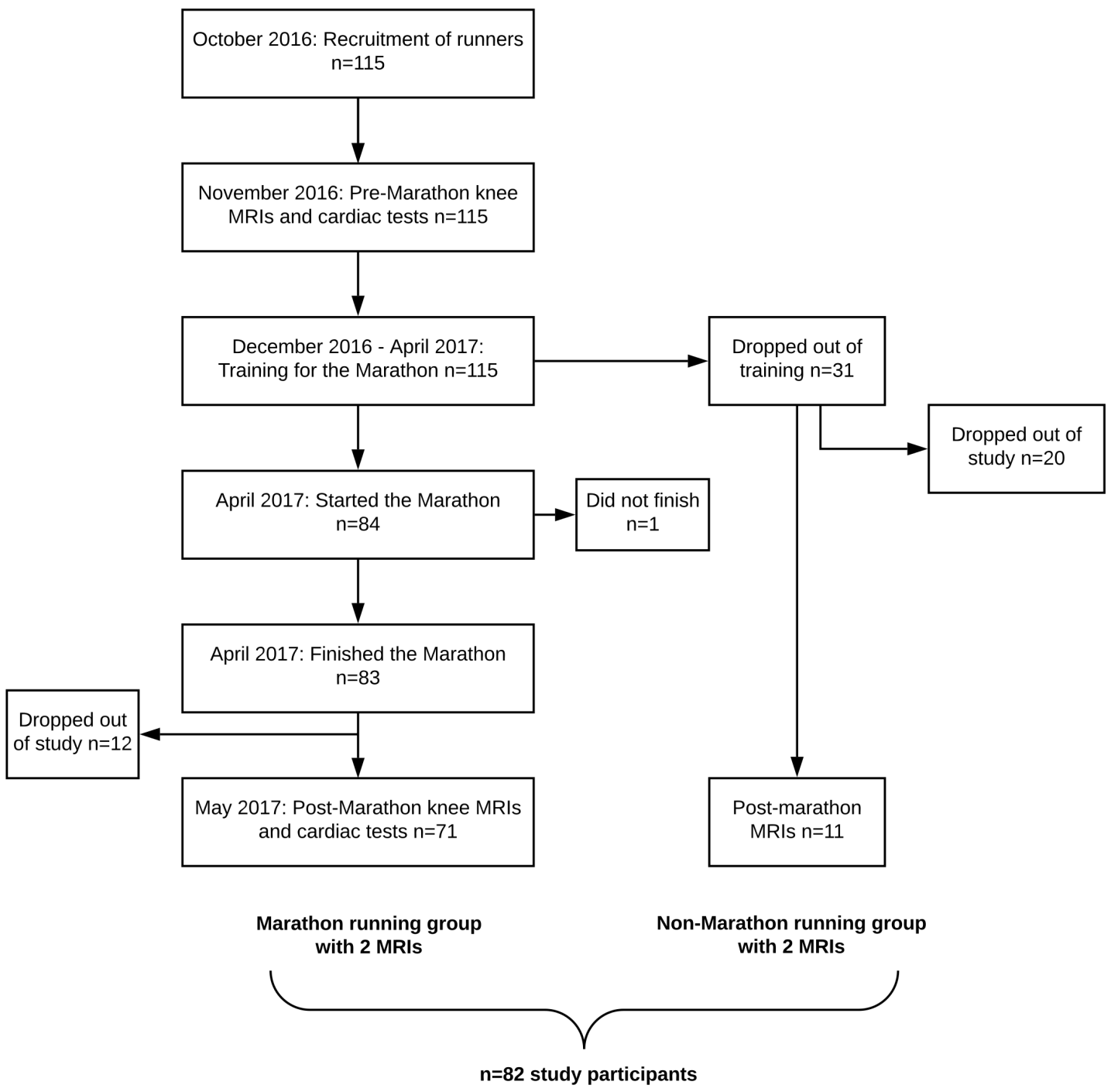

Figure 1 Recruitment and enrolment of study participants. 
Table 1 Baseline characteristics of study participants

\begin{tabular}{lll}
\hline Characteristics & $\begin{array}{l}\text { Marathon } \\
\text { runners } \mathbf{n = 7 1}\end{array}$ & $\begin{array}{l}\text { Non-marathon } \\
\text { runners } \\
\mathbf{n}=\mathbf{1 1}\end{array}$ \\
\hline Age (years) & $44 \pm 8.5$ & $44 \pm 7.0$ \\
BMl $\left(\mathrm{kg} / \mathrm{m}^{2}\right)$ & $25.2 \pm 3.6$ & $24.2 \pm 2.2^{*}$ \\
Height $(\mathrm{cm})$ & $171 \pm 9.2$ & $176 \pm 10.7$ \\
Male : Female ratio† & $32: 39$ & $5: 6$ \\
\hline
\end{tabular}

Values are reported as mean \pm SD for normally distributed data. *There were two outliers for BMI $\left(\geq 30 \mathrm{~kg} / \mathrm{m}^{2}\right)$ so we excluded those participants from the BMI analysis.

†Average and measure of spread do not apply for categorical data.

BMI, body mass index.

\section{Participant self-assessment questionnaire}

The Knee Injury and Osteoarthritis Outcome Score (KOOS) was used as a self-reported questionnaire of the knee condition and associated injuries that can result in osteoarthritis. ${ }^{19}$ The assessment is divided into five categories: pain, other symptoms, function in daily living, knee-related quality of life and function in sport and recreation. Participants were asked to complete the questionnaire both before and after the marathon to assess their perceived knee joint health. Each question was provided with five potential answers and marked from zero to four. The sum of the scores from each category was converted into a $0-100$ scale, with zero indicating extreme knee problems and 100 indicating no knee problems.

\section{Magnetic resonance imaging}

An MRI was performed on each participant 6 months before the marathon (and therefore before the standardised training programme), and then half a month after the marathon. Both knees of marathon runners were analysed using a 3.0 T MR scanner (Prisma, Siemens Healthcare, Erlangen, Germany) and dedicated knee coil. The imaging protocol included proton density-weighted fat suppressed (PD FS) sequences in axial [repetition time (TR) msec/echo time (TE) msec; 4630/37], sagittal $(4200 / 41 \mathrm{~ms})$ and coronal planes $(5240 / 41 \mathrm{~ms})$. All slices were $3 \mathrm{~mm}$ thick, with an image size/acquisition matrix of $320 \times 320$ pixels. The total acquisition time per bilateral scans was $25 \mathrm{~min}$.

\section{Radiological reporting/image analysis}

All MR images were reviewed using a picture archiving and communications system workstation by a musculoskeletal radiologist $(\mathrm{AF})$ with 10 years experience at consultant level. 30\% of the cohort (92 MRI scans from two time points of 46 knees from 23 volunteers; randomly-selected) were additionally and independently

Table 2 Number of postmarathon lesions in different structures before and after the marathon/training, in 142 knees of 71 marathon runners and 22 knees of 11 non-marathon runners

\begin{tabular}{|c|c|c|c|c|c|c|}
\hline \multirow{3}{*}{$\begin{array}{l}\text { Knee } \\
\text { abnormalities per } \\
\text { structure }\end{array}$} & \multicolumn{3}{|c|}{$\begin{array}{l}\text { Marathon runners } \\
\text { ( } n=142 \text { knees) }\end{array}$} & \multicolumn{3}{|c|}{$\begin{array}{l}\text { Non-marathon runners } \\
\text { ( } n=22 \text { knees) }\end{array}$} \\
\hline & \multicolumn{2}{|c|}{ Number of Post-M lesions } & \multirow[b]{2}{*}{$\begin{array}{l}\text { Significant change } \\
\text { from Pre-M }\end{array}$} & \multicolumn{2}{|c|}{ Number of Post-M lesions } & \multirow{2}{*}{$\begin{array}{l}\text { Significant } \\
\text { change from } \\
\text { Pre-M }\end{array}$} \\
\hline & $\begin{array}{l}\text { New/ } \\
\text { Worsened* }\end{array}$ & Improved† & & $\begin{array}{l}\text { New/ } \\
\text { Worsened }\end{array}$ & Improved & \\
\hline Meniscal tears & 1 & 0 & n.s. & 0 & 0 & n.s. \\
\hline Cartilage lesions & 25 & 2 & \multirow{3}{*}{$\begin{array}{l}\text { Lateral patella } \\
p=0.0005^{\star}\end{array}$} & 4 & 0 & \multirow[t]{3}{*}{ n.s. } \\
\hline Patello-femoral & 21 & 1 & & 3 & 0 & \\
\hline Tibio-femoral & 4 & 1 & & 1 & 0 & \\
\hline BME lesions & 26 & 23 & \multirow{3}{*}{$\begin{array}{l}\text { Medial tibia } \\
p=0.011 \dagger\end{array}$} & 3 & 3 & \multirow[t]{3}{*}{ n.s. } \\
\hline Patello-femoral & 19 & 2 & & 3 & 1 & \\
\hline Tibio-femoral & 7 & 21 & & 0 & 2 & \\
\hline Tendon lesions & 13 & 2 & $\begin{array}{l}\text { Semimembranosus } \\
p=0.016^{\star}\end{array}$ & 2 & 0 & n.s. \\
\hline Ligament lesions & 2 & 2 & n.s. & 0 & 0 & n.s. \\
\hline ITBFS & 15 & 0 & $\begin{array}{l}\text { ITB } \\
p<0.0001^{*}\end{array}$ & 1 & 1 & n.s. \\
\hline Prepatellar bursitis & 7 & 0 & $\begin{array}{l}\text { Prepatellar bursitis } \\
p=0.016\end{array}$ & 1 & 0 & n.s. \\
\hline
\end{tabular}

All abnormalities were recorded including Grade 1 abnormalities (all grades different from 0 were defined as 'lesions'). P values $<0.05$ indicate significant changes in the knees between the premarathon and postmarathon time points.See online supplementary appendices 2 and 4 for further details.

*Indicate significant worsening.

†Indicate significant improvement in the extent of lesion.

BME, bone marrow oedema; ITBFS, iliotibial band friction syndrome; n.s., not significant; Post-M, post-marathon; Pre-M, pre-marathon. 


\section{Pre-Marathon}

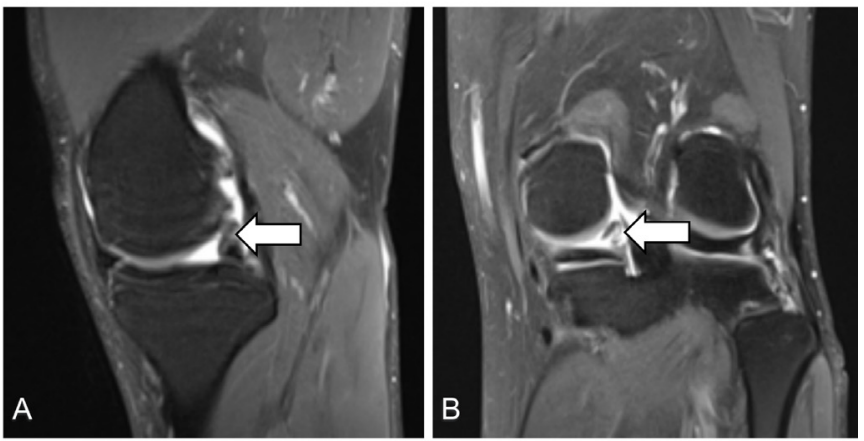

Post-Marathon
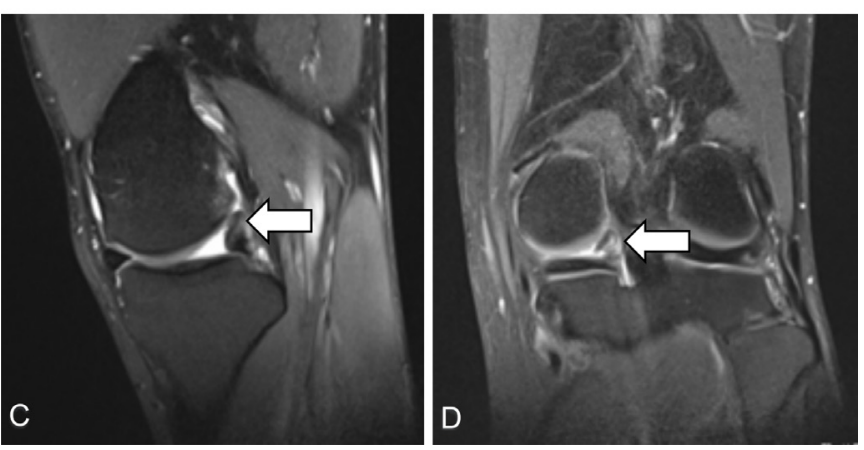

Figure $2 \mathrm{MRI}$ scans of a 45 year old marathon runner with finishing time 3 hours and 51 min who was diagnosed during the pretraining period with bucket-handle tear of the posterior horn of the medial meniscus as it is indicated by $(A)$ the sagittal PD FS image ( $T R=4670, T E=41$, slice thickness: $3 \mathrm{~mm}$ ) (white arrow) and the (B) coronal PD FS image ( $T R=5240, T E=41$, slice thickness: $3 \mathrm{~mm}$ ) where the meniscal flap within the intercondylar notch (arrow) is shown. The status of the meniscal tear did not change in 2 weeks after the marathon (see C, (D)). PD FS, proton density-weighted fat suppressed; TR, repetition time; TE, echo time.

evaluated, by a second fellowship-trained musculoskeletal radiologist with 9 years experience at consultant level (AHir). The two examiners were blinded to the baseline characteristics of the volunteers. Images of both time points were separately analysed.

In case of discrepancies between the radiologists' evaluation, consensus scores were achieved after consultation.

\section{Quantification of MRI findings}

Findings of the knee joint from MRIs were analysed using different validated scoring systems for the presence of any signal changes/lesions of varying severity: menisci, ${ }^{20}{ }^{21}$ cartilage,${ }^{22}$ bone marrow, ${ }^{23}$ tendons, ${ }^{24}$ ligaments. ${ }^{21}$ Other findings were also specified, using a binary scoring system. ${ }^{25}$ All abnormalities were recorded including Grade 1 abnormalities (all scores/grades different from zero were defined as 'lesions' throughout the text). The scoring systems are summarised in online supplementary appendix 1 .

In addition, we analysed the presence/absence of meniscal tears prior to the run versus the participants' marathon finishing times, to understand whether the presence of asymptomatic meniscal tears affected their performance.

For assessment purposes the patella was divided anatomically into medial and lateral regions, with the ridge being considered as part of the medial region. The tibia was divided into medial and lateral regions and the femur was divided into medial, lateral and trochlea regions and the trochlea was further divided into medial, central, lateral. The medial and lateral menisci were each divided into two subregions: anterior horn and posterior horn. Scores were assigned for each individual region.

\section{Statistical analysis}

Both knees of the same subject were examined and each knee was treated independently in the statistical analysis. The data was summarised and then comparisons were made between groups of data. Unpaired t-test was used to assess any significant differences between marathon runners and non-marathon runners with respect to age and height. Two sample t-test was used to assess any significant differences between the two groups with respect to body mass index (BMI). $\chi^{2}$ test was used for comparison of gender differences between the two groups. Changes between premarathon and postmarathon BMI were analysed using paired t-test in marathon runners and non-marathon runners, respectively. Wilcoxon test was used to assess significant differences between 6 months premarathon and half a month postmarathon scores/ grades for each knee feature, as well as premarathon and postmarathon participant KOOS results for each questionnaire item. Statistical significance was defined as p $<0.05$ (GraphPad Prism, V.6.0 c).

\section{Patient and public involvement}

This research would not have been possible without the involvement of the runners who were successful in the ballot for the London Marathon 2017 and volunteered to participate in the study. No participants were directly involved in the design, recruitment, or conduct of the study. However, the participants were made aware of their contribution of clinical data to research through their informed consents. After publication, dissemination of the results will be sought across social media and scientific meetings. Also, a summary report of the study results was sent to participants informing them about our findings and implications.

\section{RESULTS}

Before the marathon, 115 volunteers underwent MRI of both knees (230 MRI scans) and 82 out of them came back for another set of scans after the marathon and/or training (164 MRI scans). Here, we report any changes seen in the 164 knees when the premarathon MRI was compared with the postmarathon MRI for each knee structure. We have also compared findings between the runners $(\mathrm{n}=71,142$ knees $)$ and the non-marathon runners ( $\mathrm{n}=11,22$ knees). Full details were given in online supplementary appendix 2. 
Cartilage: Marathon runners ( $n=71,142$ knees)

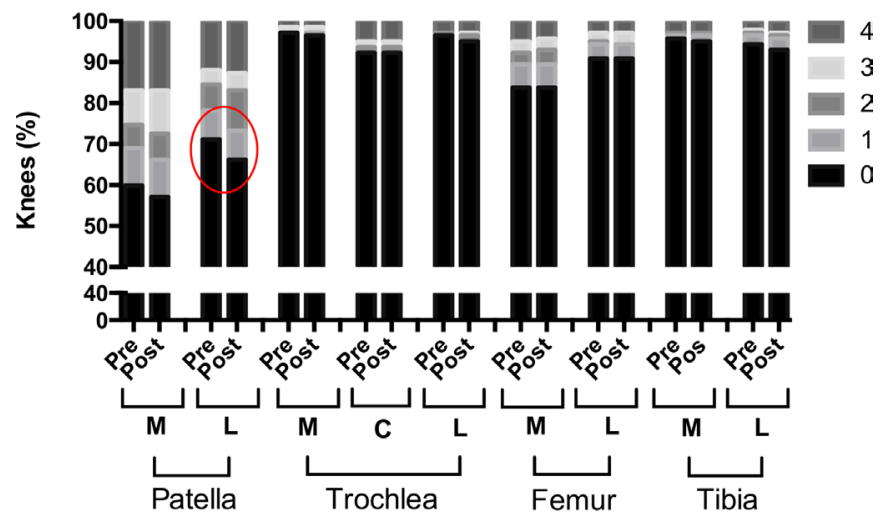

Cartilage: Non-Marathon runners ( $n=11,22$ knees)

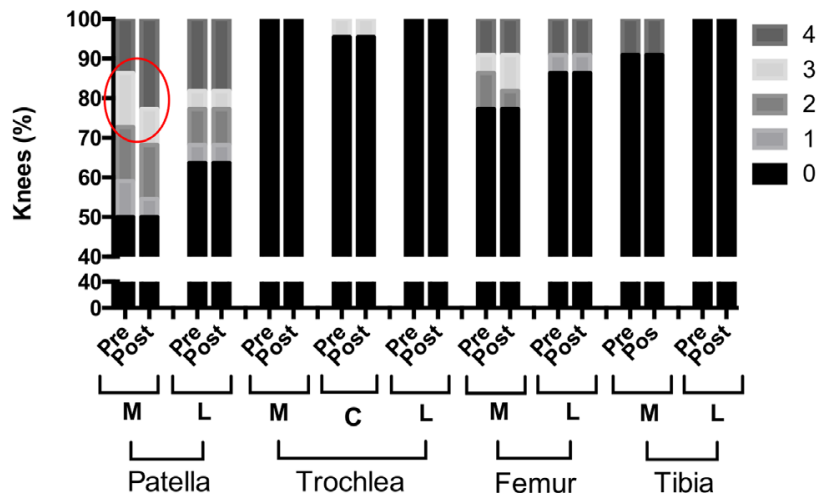

Figure 3 The prevalence of knees with premarathon and postmarathon cartilage lesions in marathon runners and non-marathon runners. The lesions were graded using the modified Noyes and Stabler scoring system and scores 0-4 were assigned: 1 -areas of heterogeneous signal intensity on fat saturated IW FSE sequences; 2-cartilage defects that involve less than 1/2 of cartilage thickness; 3-cartilage defects that involve more than $1 / 2$ of cartilage thickness but less than full thickness. 4-full thickness cartilage defects exposing the bone. Red circles indicate changes in the grading of lesions in the knees of participants between the premarathon and postmarathon scans. C, central; L, lateral; $\mathrm{M}$, medial; IW FSE, intermediate-weighted fast spin-echo.

\section{Participant characteristics}

There were no significant differences between the two groups of volunteers (marathon and non-marathon runners) with regards to age $(\mathrm{p}=0.795)$, BMI at the beginning of the study $(\mathrm{p}=0.375)$, height $(\mathrm{p}=0.264)$ and gender (0.981).

A significant difference between preBMI and postBMI datasets in marathon runners $(p=0.009)$ were noted and no significant difference in non-marathon runners $(\mathrm{p}=0.800)$ (see online supplementary appendix 3$)$. The majority of marathon runners $(67 \%)$ reduced their BMI as a result of the marathon training, with the median value reduced from $25.2 \pm 3.6$ to $24.9 \pm 3.5$.

The mean marathon finishing time was 5 hours $20 \mathrm{~min}$.

\section{KOOS analysis}

Seventy out of the 82 participants completed KOOS questionnaires both before and after the marathon:
$65 / 71$ marathon runners and 5/11 non-marathon runners. Both premarathon and postmarathon KOOS scores in marathon runners and non-marathon runners were normally distributed. No significant changes between premarathon and postmarathon KOOS scores were identified in runners for the individual questionnaire items related to: symptoms $(\mathrm{p}=0.981)$, pain $(\mathrm{p}=0.121)$, daily activity $(\mathrm{p}=0.303)$, sports and recreational activities $(p=0.133)$, quality of life $(p=0.096)$. No significant differences between the same two scanning time points were reported among non-marathon runners: symptoms $(\mathrm{p}=0.375)$, pain $(\mathrm{p}=0.250)$, daily activity $(p>0.999)$, sports and recreational activities $(p$ $p>0.999)$, quality of life $(p=0.250)$ (see online supplementary appendix 3 ).

\section{Meniscus}

Before the marathon, 51 (36\%) of 142 knees, of those who finished the marathon, had meniscal tears (figure 2) and 23 knees $(16 \%)$ had meniscal signal hyperintensity. There were no significant differences in prevalence of meniscal lesions between premarathon and postmarathon scans. After the marathon, only one runner showed an increased grade from a normal meniscus to horizontal tear in the left knee (table 2; 40-year-old woman; marathon finishing time: 6 hours $20 \mathrm{~min}$ ). Menisci of all other scanned knees remained unchanged. The majority of the meniscal lesions $(83 \%)$ were seen in the posterior horn of the medial meniscus.

Out of the 84 participants who entered the race, 37 were diagnosed with meniscal tears and 47 were tear-free at the premarathon/pretraining MRI scan (online supplementary appendix 5). Only one participant who had a meniscal tear did not finish the marathon and this participant was not included in the statistical analysis. There was no significant difference in the finishing times between the two groups (meniscal tear present/meniscal tear absent) $(\mathrm{p}=0.135$; online supplementary appendix 5).

In non-marathon runners, six out of 22 knees $(27 \%)$ had meniscal tears and five knees (23\%) presented with meniscal signal hyperintensity at the first time point of scanning. No change was seen after the marathon (table 2).

\section{Articular cartilage}

Before the marathon, more than half of the knees, of those that went on to finish the marathon, already had cartilage damage (92 knees, $65 \%$ ), with the majority of lesions located in the patellofemoral joint $(70 \%)$ and all were asymptomatic. The patellofemoral joint was most affected after the marathon (21 cartilage lesions), especially the lateral patellar facet (12 lesions, $\mathrm{p}=0.0005$; table 2; figure 3; online supplementary appendix 6 figure 2; online supplementary appendices 7 and 8 ).

Similarly, in non-marathon runners, more than half of the knees had cartilage lesions (15 out of 22 knees, $68 \%$ ) prior to training. After training, four lesions worsened (table 2), with three of them being located in the patella (online supplementary appendix 8). 
BME: Marathon runners ( $n=71,142$ knees)

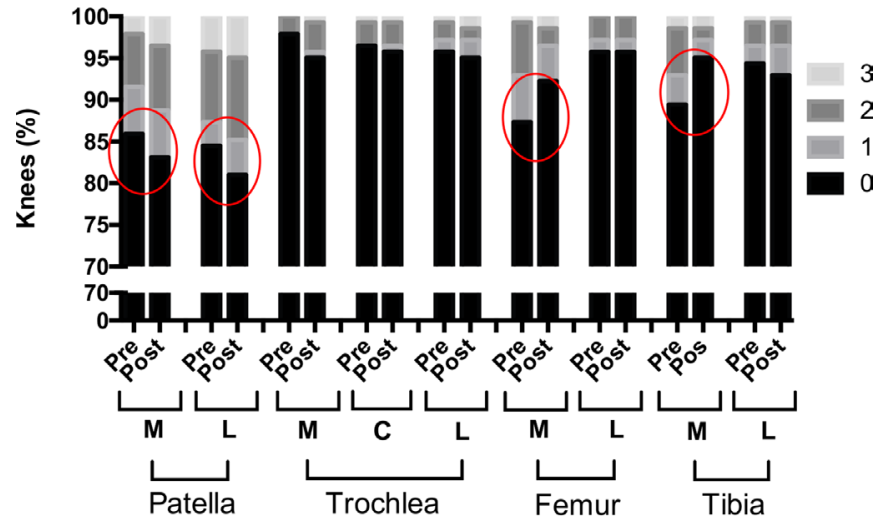

BME: Non-Marathon runners ( $n=11,22$ knees)

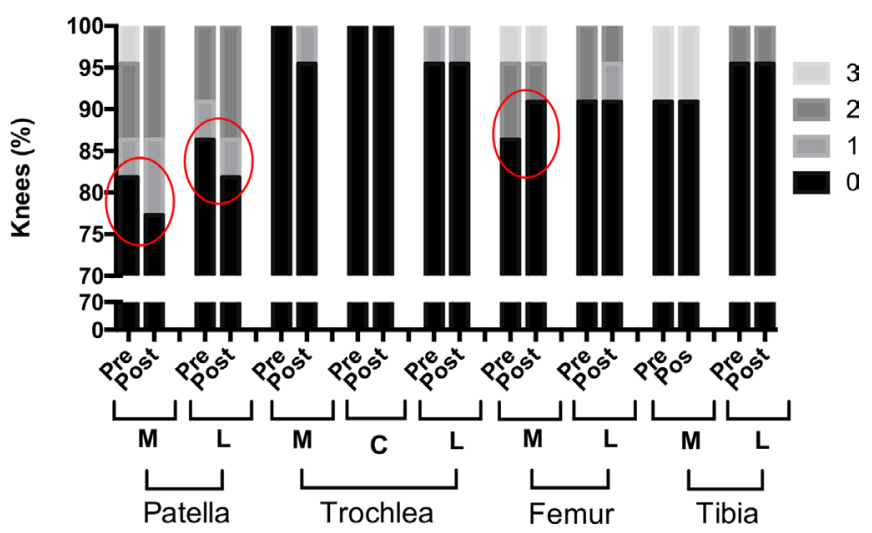

Figure 4 The prevalence of knees with premarathon and postmarathon subchondral BME in marathon runners and non- marathon runners. The lesions were graded using the KOSS scoring system and scores $0-3$ were assigned: $0-$ absent; 1-minimal ( $d<5 \mathrm{~mm})$; 2-moderate $(\mathrm{d}=5-20 \mathrm{~mm})$; 3 - severe $(\mathrm{d}>=20 \mathrm{~mm})$. Red circles indicate changes in the grading of lesions in the knees of participants between the premarathon and postmarathon scans. BME, bone marrow oedema; C, central; d, diameter; KOSS, Knee Osteoarthritis Scoring System; L, lateral; M, medial.

\section{Subchondral bone marrow}

Before the marathon, subchondral bone marrow oedema (BME) was present in 58 knees $(41 \%)$, of those that went on to finish the marathon, with over half of the lesions in the patella-femoral joint (54\%) (figure 4) After the marathon, the patellofemoral joint had the highest number of new/worsened lesions (19 lesions; table 2; online supplementary appendix 6 - figures 3 and 4), although of no statistical significance. However, improvement was noted in the medial compartment BME with 10 lesions improved in the tibia $(p=0.011)$ and nine lesions improved in the femur ( $p=0.082$; table 2; online supplementary appendices 7 and 8). In non-marathon runners, nine out of 22 knees $(41 \%)$ had BME before training. After training, there were three additional patellar lesions and three other lesions improved (online supplementary appendix 6 - figure 4 ; online supplementary appendix 7).

\section{Tendons}

Before the marathon, tendon injuries were present in 60 knees $(42 \%)$, of those that went on to finish the marathon, with the majority being patellar tendon, followed by quadriceps, semimembranosus tendon and lastly a small number of other tendons. Postmarathon, six new insertional semimembranosus tendon injuries appeared ( $\mathrm{p}=0.016$; table 2; online supplementary appendices 5 and 6). In non-marathon runners, five knees (23\%) had tendon lesions before training. Post-training, two previously healthy knees developed patellar tendon lesions (table 2; online supplementary appendix 7).

\section{Ligaments}

Before the marathon, 59 knees (42\%), of those that went on to finish the marathon, had ligamentous lesions, with the vast majority being found in the anterior cruciate ligament (ACL; 90\%), and few in the medial collateral ligament (MCL; 7\%) and lateral collateral ligament (LCL; 3\%; table 2).

Only the collateral ligaments were minimally changed after the run: medial (two lesions resolved), lateral (two lesions appeared; table 2; online supplementary appendices 7 and 8). In non-marathon runners, seven knees $(32 \%)$ had ligamentous lesions before training. No change was recorded after the training (table 2; online supplementary appendix 7).

\section{Other findings}

Before the marathon, a number of marathon runners' knees had: joint effusion (52\%), Baker's cyst (34\%), prepatellar bursitis $(25 \%)$ and iliotibial band friction syndrome (ITBFS) (2\%).

After the marathon, there was a significant increase in the number of knees with prepatellar bursitis (seven lesions; $p=0.016$ ) and ITBFS (15 lesions; $p<0.0001$ ) (table 2). Similarly, joint effusions (50\%), Baker's cysts $(41 \%)$ and prepatellar bursitis (27\%) were prevalent in non-marathon runners before the training. After training, the levels of these remained almost unchanged.

\section{Dual reporting}

No major discrepancies between the scores of the two radiologists were reported (30\% participants). For patellar cartilage we found differences in the radiologists' scores in $30 \%$ of the scans at the two time points, but consensus scores were achieved after consultation between radiologists.

\section{DISCUSSION}

\section{Principal findings}

Data from MRI scans of 164 knees from 82 novice, middleaged marathon runners found damage in some areas of the knee (lateral patella cartilage and bone, the iliotibial band) and improvement in other areas (subchondral bone of the femoral and tibial condyles) as a result of training for, and running a marathon. Meniscal damage did not prevent marathon running. 


\section{Strengths and weaknesses}

Crucial to this study design was the recruitment of middle-aged volunteers because they had a large number of asymptomatic knee abnormalities on MRI prior to training/running: this enabled us to examine both increased and decreased damage to identify those structure at risk and those that benefit from long distance running. Additionally, this is the largest and most detailed study of the knees of middle-aged marathon runners. Detailed assessment of each knee structure was made from 3T MRI, which is the highest resolution in clinical use and enabled greater diagnostic confidence. ${ }^{89}$

We acknowledged the following limitations: first, MRI reporting involves a certain level of bias but we tried to minimise it by involving two independent radiologists in the image analysis. Second, prestudy lifestyle details such as sport activities were not available and could not be accounted for; however, the participants were sedentary at recruitment and followed a standardised training programme premarathon. Lastly, the exact times of dropping out from training by non-marathon runners were unavailable and could not be commented on.

\section{Comparison with previous studies}

Only a few marathon studies have used 3T MRI, ${ }^{12} 1516$ and none of these had a sample size greater than 22. ${ }^{1}{ }^{10} 12-17$ Limitations of these studies include short follow-up and absence of controls.

There is some agreement between our findings and other marathon studies. Similar to our study results, Schueller-Weidekamm et $a l^{13}$ showed no increase in intrameniscal signal intensity after the marathon except in one case. In agreement with our study, signal alterations in the ACL, patellar tendon and joint effusions were seen before the marathon at a relatively high level, with little to no change after the run. ${ }^{6}$

The evidence on BME is conflicting. Stahl et $a l^{15}$ reported BME in $50 \%$ of marathon runners' knees and there was an increase in the extent of oedema in $20 \%$ of the affected knees after the run. While the majority of other studies ${ }^{1012} 13$ did not show significant bone marrow changes. Our study is the first to show improvement in the subchondral BME as a result of running a marathon.

Schueller-Weidekamm et $a l^{\text {s }}$ study ${ }^{13}$ showed a much lower prevalence of cartilage lesions before the marathon, with $18 \%$ knees affected (the specific location of lesions was not reported), while our study had $65 \%$ of knees affected. Additionally, they found no change after the run while we found a significant increase in patella cartilage lesions.

\section{Clinical significance}

The improvements seen in the BME of the subchondral bone of the medial compartment may suggest that marathon running and/or training could have a protective effect on the knee joints of sedentary asymptomatic individuals. ${ }^{26-28}$ Perhaps regular running prevents medial compartment overload due to muscle strengthening. ${ }^{29} 30$ Further investigations are needed involving longer follow-up but the implications of these findings are important because subchondral bone marrow defects are linked with the onset of osteoarthritis, ${ }^{31-33}$ and exercise is recommended for the treatment of osteoarthritis.

Our study helps to understand the optimal dose of exercise for human knee joints. Marathon training and running may be above the dose recommended for the patellofemoral joint: or recovery treatments should be targeted at this area of the knee. However, marathon seems to be a satisfactory dose of exercise for the medial and lateral tibio-femoral joints.

Before the marathon we found a number of asymptomatic meniscal tears-including bucket-handle tears. After the marathon, the tears did not develop further, supporting conservative/non-surgical management of meniscal injuries in general, if asymptomatic.

\section{Unanswered questions and future research}

We question whether the lesions that appeared/worsened from pre-existing ones after the marathon resolve at a long-term follow-up. Further research is required to clarify whether the marathon damage to the knee joint structures is permanent and how serious it is.

Acknowledgements We thank all the study participants who allowed their clinical details to be used for research and educational purposes. We also thank the investigators and institutions: University College London, the Royal National Orthopaedic Hospital, St George's University Hospitals, Barts Health NHS Trust, the London Implant Retrieval Centre; for their involvement in the research.

\section{Contributors}

LMH, JH, AF, AHir, CT, ADS, SS, JM and AH developed the study concept and design. $\mathrm{LMH}, \mathrm{JH}, \mathrm{AF}, \mathrm{CT}, \mathrm{ADL}, \mathrm{ADS}$, SS, JM and AH contributed to the acquisition of data. LMH, AF, AHir contributed to the analysis of data. LMH, JH, AF, AHir, JM and $\mathrm{AH}$ contributed to the interpretation of data. LMH conducted the statistical analysis. All authors were involved in writing the manuscript. LMH, JH, JM and AH obtained the funding for the study data and analysis. LMH, CT, JM provided administrative, technical, material support for the study analysis. AH is the study supervisor. All authors had full access to the data in the study and can take responsibility for the integrity of the data and the accuracy of the data analysis. $\mathrm{AH}$ is the guarantor. The corresponding author $\mathrm{LMH}$ attests that all listed authors meet authorship criteria and that no others meeting the criteria have been omitted.

Funding This research study was funded by patient donations and supported by researchers at the National Institute for Health Research University College London Hospitals Biomedical Research Centre. The authors are also grateful to The Maurice Hatter Foundation, the RNOH Charity and the Rosetrees Trust for their support.

Competing interests None declared.

Patient consent for publication Obtained.

Ethics approval The study was approved by NHS Research Ethics Committee (REC Reference Number 15/L0/0086).

Provenance and peer review Not commissioned; externally peer reviewed.

Data availability statement Data are available upon reasonable request.

Open access This is an open access article distributed in accordance with the Creative Commons Attribution Non Commercial (CC BY-NC 4.0) license, which permits others to distribute, remix, adapt, build upon this work non-commercially, and license their derivative works on different terms, provided the original work is properly cited, appropriate credit is given, any changes made indicated, and the use is non-commercial. See: http://creativecommons.org/licenses/by-nc/4.0/.

\section{ORCID iDs}

Laura Maria Horga http://orcid.org/0000-0003-1244-2140

Andrew D'Silva http://orcid.org/0000-0002-8700-1545 


\section{REFERENCES}

1 Krampla W, Mayrhofer R, Malcher J, et al. Mr imaging of the knee in marathon runners before and after competition. Skeletal Radiol 2001;30:72-6.

2 Cheng Y, Macera CA, Davis DR, et al. Physical activity and selfreported, physician-diagnosed osteoarthritis: is physical activity a risk factor? J Clin Epidemiol 2000;53:315-22.

3 Cymet TC, Sinkov V. Does long-distance running cause osteoarthritis? J Am Osteopath Assoc 2006:106:342-5.

4 Satterthwaite P, Larmer P, Gardiner J, et al. Incidence of injuries and other health problems in the Auckland Citibank marathon, 1993. $\mathrm{Br} J$ Sports Med 1996;30:324-6.

5 Fredericson M, Misra AK. Epidemiology and aetiology of marathon running injuries. Sports Medicine 2007;37:437-9.

6 Lepers R, Cattagni T. Do older athletes reach limits in their performance during marathon running? Age 2012;34:773-81.

7 Jokl P, Sethi PM, Cooper AJ. Master's performance in the new York City marathon 1983-1999. Br J Sports Med 2004;38:408-12.

8 Wong S, Steinbach L, Zhao J, et al. Comparative study of imaging at 3.0 T versus 1.5 T of the knee. Skeletal Radiol 2009;38:761-9.

9 Fischbach F, Bruhn H, Unterhauser F, et al. Magnetic resonance imaging of hyaline cartilage defects at 1.5T and 3.0T: comparison of medium T2-weighted fast spin echo, T1-weighted two-dimensional and three-dimensional gradient echo pulse sequences. Acta radiol 2005;46:67-73.

10 Hohmann E, Wörtler K, Imhoff AB. Mr imaging of the hip and knee before and after marathon running. Am J Sports Med 2004;32:55-9.

11 Kursunoglu-Brahme S, Schwaighofer B, Gundry C, et al. Jogging causes acute changes in the knee joint: an Mr study in normal volunteers. American Journal of Roentgenology 1990;154:1233-5.

12 Luke AC, Stehling C, Stahl R, et al. High-Field magnetic resonance imaging assessment of articular cartilage before and after marathon running: does long-distance running lead to cartilage damage? Am J Sports Med 2010;38:2273-80.

13 Schueller-Weidekamm C, Schueller G, Uffmann M, et al. Does marathon running cause acute lesions of the knee? evaluation with magnetic resonance imaging. Eur Radiol 2006;16:2179-85.

14 Shellock FG, Deutsch AL, Mink JH, et al. Do asymptomatic marathon runners have an increased prevalence of meniscal abnormalities? an Mr study of the knee in 23 volunteers. AJR Am J Roentgenol 1991;157:1239-41.

15 Stahl R, Luke A, Ma CB, et al. Prevalence of pathologic findings in asymptomatic knees of marathon runners before and after a competition in comparison with physically active subjects-a 3.0 T magnetic resonance imaging study. Skeletal Radiol 2008;37:627-38.

16 Stehling C, Luke A, Stahl R, et al. Meniscal T1rho and T2 measured with 3.0T MRI increases directly after running a marathon. Skeletal Radiol 2011;40:725-35

17 Kessler MA, Glaser C, Tittel S, et al. Recovery of the menisci and articular cartilage of runners after cessation of exercise: additional aspects of in vivo investigation based on 3-dimensional magnetic resonance imaging. Am J Sports Med 2008;36:966-70.

18 Ekelund U, Steene-Johannessen J, Brown WJ, et al. Does physical activity attenuate, or even eliminate, the detrimental association of sitting time with mortality? A harmonised meta-analysis of data from more than 1 million men and women. Lancet 2016;388:1302-10.

19 Roos EM, Lohmander LS. The knee injury and osteoarthritis outcome score (KOOS): from joint injury to osteoarthritis. Health and Quality of Life Outcomes 2003;1.

20 Hunter DJ, Lo GH, Gale D, et al. The reliability of a new scoring system for knee osteoarthritis MRI and the validity of bone marrow lesion assessment: BLOKS (Boston-Leeds osteoarthritis knee score). Ann Rheum Dis 2008;67:206-11.

21 Roemer FW, Frobell R, Lohmander LS, et al. Anterior cruciate ligament osteoarthritis score (ACLOAS): longitudinal MRI-based whole joint assessment of anterior cruciate ligament injury. Osteoarthritis and Cartilage 2014;22:668-82.

22 Recht MP, Piraino DW, Paletta GA, et al. Accuracy of fat-suppressed three-dimensional spoiled gradient-echo flash MR imaging in the detection of patellofemoral articular cartilage abnormalities. Radiology 1996;198:209-12.

23 Kornaat PR, Ceulemans RYT, Kroon HM, et al. MRI assessment of knee osteoarthritis: Knee Osteoarthritis Scoring System (KOSS)?inter-observer and intra-observer reproducibility of a compartment-based scoring system. Skeletal Radiol 2005;34:95-102.

24 el-Khoury GY, Wira RL, Berbaum KS, Monu J, et al. Mr imaging of Patellar tendinitis. Radiology 1992;184:849-54.

25 Hunter DJ, Guermazi A, Lo GH, et al. Evolution of semi-quantitative whole joint assessment of knee oa: MOAKS (MRI osteoarthritis knee score). Osteoarthritis and Cartilage 2011;19:990-1002.

26 Spector TD, Harris PA, Hart DJ, et al. Risk of osteoarthritis associated with long-term weight-bearing sports: a radiologic survey of the hips and knees in female ex-athletes and population controls. Arthritis Rheum 1996;39:988-95.

27 Hyldahl RD, Evans A, Kwon S, et al. Running decreases knee intraarticular cytokine and cartilage oligomeric matrix concentrations: a pilot study. Eur J Appl Physiol 2016;116:2305-14.

28 Timmins KA, Leech RD, Batt ME, et al. Running and knee osteoarthritis: a systematic review and meta-analysis. Am J Sports Med 2017;45:1447-57.

29 Bennell KL, Hunt MA, Wrigley TV, et al. The effects of hip muscle strengthening on knee load, pain, and function in people with knee osteoarthritis: a protocol for a randomised, single-blind controlled trial. BMC Musculoskelet Disord 2007;8.

30 Fransen M, Crosbie J, Edmonds J. Physical therapy is effective for patients with osteoarthritis of the knee: a randomized controlled clinical trial. J Rheumatol 2001;28:156-64.

31 Link T, Li X. Bone marrow changes in osteoarthritis. Semin Musculoskelet Radiol 2011;15:238-46.

32 Sudoł-Szopińska I, Kontny E, Maśliński W, et al. Significance of bone marrow edema in pathogenesis of rheumatoid arthritis. Pol J Radiol 2013;78:57-63.

33 Li G, Yin J, Gao J, et al. Subchondral bone in osteoarthritis: insight into risk factors and microstructural changes. Arthritis Res Ther 2013;15. 